\title{
In Vitro Fumonisin Biosynthesis and Genetic Structure of Fusarium verticillioides Strains from Five Mediterranean Countries
}

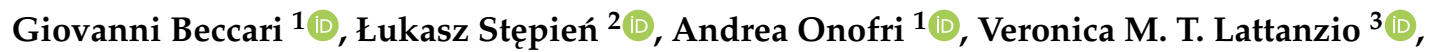 \\ Biancamaria Ciasca ${ }^{3}$, Sally I. Abd-El Fatah ${ }^{4}$, Francesco Valente ${ }^{1}$, Monika Urbaniak ${ }^{2} \mathbb{D}$ and \\ Lorenzo Covarelli ${ }^{1, *,+}$
}

1 Department of Agricultural, Food and Environmental Sciences, University of Perugia, 06121 Perugia, Italy; giovanni.beccari@unipg.it (G.B.); andrea.onofri@unipg.it (A.O.); fv220@exter.ac.uk (F.V.)

2 Department of Pathogen Genetics and Plant Resistance, Institute of Plant Genetics, Polish Academy of Sciences, 60-479 Poznan, Poland; lste@igr.poznan.pl (Ł.S.); murb@igr.poznan.pl (M.U.)

3 National Research Council of Italy, Institute of Sciences of Food Production (ISPA-CNR), 70126 Bari, Italy; veronica.lattanzio@ispa.cnr.it (V.M.T.L.); biancamaria.ciasca@ispa.cnr.it (B.C.)

4 Food Toxins and Contaminants Department, National Research Centre, Cairo 12622, Egypt; simaged@yahoo.com

* Correspondence: lorenzo.covarelli@unipg.it; Tel.: +39-0755856464

+ Current co-address: Centre for Crop and Disease Management, School of Molecular and Life Science, Curtin University, Bentley, Perth 6102, Australia.

Received: 24 January 2020; Accepted: 6 February 2020; Published: 11 February 2020

\begin{abstract}
Investigating the in vitro fumonisin biosynthesis and the genetic structure of Fusarium verticillioides populations can provide important insights into the relationships between strains originating from various world regions. In this study, $90 \mathrm{~F}$. verticillioides strains isolated from maize in five Mediterranean countries (Italy, Spain, Tunisia, Egypt and Iran) were analyzed to investigate their ability to in vitro biosynthesize fumonisin $B_{1}$, fumonisin $B_{2}$ and fumonisin $B_{3}$ and to characterize their genetic profile. In general, $80 \%$ of the analyzed strains were able to biosynthesize fumonisins (range 0.03-69.84 $\mu \mathrm{g} / \mathrm{g}$ ). Populations from Italy, Spain, Tunisia and Iran showed a similar percentage of fumonisin producing strains ( $>90 \%)$; conversely, the Egyptian population showed a lower level of producing strains $(46 \%)$. Significant differences in fumonisin biosynthesis were detected among strains isolated in the same country and among strains isolated from different countries. A portion of the divergent FUM1 gene and of intergenic regions FUM6-FUM7 and FUM7-FUM8 were sequenced to evaluate strain diversity among populations. A high level of genetic uniformity inside the populations analyzed was detected. Apparently, neither geographical origin nor fumonisin production ability were correlated to the genetic diversity of the strain set. However, four strains from Egypt differed from the remaining strains.
\end{abstract}

Keywords: Fusarium; ear rot; maize; fumonisins; FUM1

\section{Introduction}

Fusarium verticillioides (Sacc.) Nirenberg is a member of the Gibberella fujikuroi species complex, also called Fusarium fujikuroi species complex (FFSC), a group of 40 closely related Fusarium species defined by morphological traits, sexual compatibility and DNA-based phylogenetic analysis [1,2].

In particular, F. verticillioides belongs to the "African" clade of the FFSC [3], and it is the main causal agent of Fusarium ear rot of maize (Zea mays L.) [4,5]. This fungus has been reported worldwide and, in particular, it prevails in drier and warmer climatic regions [6,7] such as those present in temperate, 
semitropical and tropical regions including European [4], Mediterranean [8], African [9] and Middle Eastern [10] maize-growing areas. For example, F. verticillioides was the species isolated more frequently from maize kernels harvested in Italy [11-13], Spain [14-16], Egypt [17-21] and Iran [22]. This is also one of the species able to biosynthesize the secondary metabolites fumonisins [23]. Specifically, F. verticillioides is considered the main fumonisin producer; therefore, this is the most important species associated with fumonisin contamination of maize grains [24]. Fumonisins occur worldwide in maize, including Mediterranean $[4,8,24,25]$ farming areas, where this is one of the most widely cultivated crops $[26,27]$. Fumonisin accumulation in maize grains can occur in the field, following preharvest infections, and possibly continue during grain storage [28].

Contaminations strongly impair maize grain quality because of the negative impact on animal and human health [29]. Fumonisin mycotoxins can be divided into four main groups, with the most abundant fumonisins found in nature included in the $B$ group: fumonisin $B_{1}\left(\mathrm{FB}_{1}\right)$, fumonisin $\mathrm{B}_{2}\left(\mathrm{FB}_{2}\right)$ and fumonisin $\mathrm{B}_{3}\left(\mathrm{FB}_{3}\right)$. Among $\mathrm{B}$ analogues, $\mathrm{FB}_{1}$ is the most detected fumonisin in maize as well as the most toxicologically active [24,30]. In fact, after ingestion, fumonisins may cause a wide range of toxic effects, especially towards liver and kidneys [31-35]. For this reason, the European Commission has established maximum limits for the sum of $\mathrm{FB}_{1}$ and $\mathrm{FB}_{2}$ in maize for human consumption $[36,37]$.

The amount of fumonisins found in maize kernels is also dependent on the toxigenic ability of the F. verticillioides populations occurring in a certain cultivated field or in a specific geographic area [38]. In fact, within the F. verticillioides species, fumonisin production commonly varies quantitatively because of the different strain abilities to biosynthesize different levels of these mycotoxins [15,24,39-41]. The amount of fumonisins produced may also vary in quantity depending on substrate [42], biotic and abiotic factors [43] as well as on the relative expression of the genes involved in the biosynthetic pathway [44]. In fact, fumonisin production in F. verticillioides is regulated by the FUM biosynthetic gene cluster [45], and some of the differences between strains can be explained by FUM gene sequence differences $[46,47]$. Thus, it is very important to determine the variations of fumonisin production by $F$. verticillioides to understand the biosynthetic potential of a certain population in a specific cultivation area.

The characterization of fumonisin biosynthesis by F. verticillioides strains isolated from different geographic areas has been often coupled to the study of the genetic structure of these populations to investigate the degree of genetic diversity between the different strains within the same species [44,48-50]. This can provide an important insight on the relationships, the variations and/or the similarities among strains originating from various regions as well as on the possible correlations between genetic variability and different fumonisin production [38,51-54]. Analyses of fumonisin biosynthesis and/or molecular characterization of $F$. verticillioides strains have been conducted in populations from different countries such as Argentina [55], Brazil [38,41,44,49], Italy [50], Iran [22,52], Ethiopia [53] and Nigeria [54].

A similar approach was adopted in the present work to characterize selected F. verticillioides strains originating from five Mediterranean countries to simultaneously compare them in a wider geographical context by evaluating their in vitro fumonisin production and genetic profile. Specifically, the main objectives of the present study were to:

(i) investigate the abilities of selected F. verticillioides strains isolated from maize kernels in five Mediterranean countries to in vitro biosynthesize $\mathrm{FB}_{1}, \mathrm{FB}_{2}$ and $\mathrm{FB}_{3}$;

(ii) characterize the genetic structure of these selected strains to assess for possible variability within strains originating from each of the surveyed countries and between the strains originating from different countries. 


\section{Materials and Methods}

\subsection{Fungal Strains}

A total of 90 F. verticillioides strains (Table 1) isolated from single maize kernels harvested from different fields in five Mediterranean countries (22 from Italy, 9 from Spain, 16 from Tunisia, 28 from Egypt and 15 from Iran) were used in this study (Figure 1). Isolation operations were carried out in the country of origin where all strains were properly stored in fungal collections. The investigated strains had not been extensively subcultured, thus avoiding possible alterations in fumonisin production. Some of the Italian strains used in this work had been already investigated in a previous study [50] and were included to further characterize them in a wider geographical context (Figure 1).

Table 1. Strain ID, country of origin and fumonisin $B_{1}$, fumonisin $B_{2}$ and fumonisin $B_{3}$ production $(\mu \mathrm{g} / \mathrm{g})$ with standard errors $( \pm \mathrm{SE})$ by Fusarium verticillioides strains isolated from maize kernels harvested in five Mediterranean countries and analyzed in this study.

\begin{tabular}{|c|c|c|c|c|c|c|c|c|c|c|}
\hline \multirow{3}{*}{$\begin{array}{l}\text { Strain ID } \\
\text { PG } 21 C\end{array}$} & \multirow{3}{*}{$\begin{array}{c}\text { Origin } \\
\text { Italy }\end{array}$} & \multicolumn{9}{|c|}{ Fumonisin Production $(\mu \mathrm{g} / \mathrm{g}) *$} \\
\hline & & \multicolumn{2}{|c|}{ Fumonisin $B_{1}$} & \multicolumn{2}{|c|}{ Fumonisin $B_{2}$} & \multicolumn{2}{|c|}{ Fumonisin $B_{3}$} & \multicolumn{3}{|c|}{ Total Fumonisins $* *, \S$} \\
\hline & & $\mathrm{nd}^{+}$ & - & nd & - & nd & - & nd & - & - \\
\hline PG 39B & Italy & nd & - & nd & - & nd & - & nd & - & - \\
\hline ITEM 9313 & Italy & 0.03 & $( \pm 0.01)$ & nd & - & nd & - & 0.03 & $( \pm 0.01)$ & $\mathrm{a}$ \\
\hline ITEM 9319 & Italy & 0.16 & $( \pm 0.08)$ & 0.03 & $( \pm 0.01)$ & 0.05 & $( \pm 0.02)$ & 0.24 & $( \pm 0.11)$ & $\mathrm{ab}$ \\
\hline PG 60A1 & Italy & 0.20 & $( \pm 0.02)$ & 0.04 & $( \pm 0.01)$ & 0.05 & $( \pm 0.01)$ & 0.29 & $( \pm 0.02)$ & $\mathrm{b}$ \\
\hline ITEM 9330 & Italy & 0.30 & $( \pm 0.08)$ & 0.05 & $( \pm 0.01)$ & 0.06 & $( \pm 0.01)$ & 0.41 & $( \pm 0.09)$ & $a b$ \\
\hline ITEM 9320 & Italy & 0.63 & $( \pm 0.60)$ & 0.10 & $( \pm 0.10)$ & 0.08 & $( \pm 0.07)$ & 0.81 & $( \pm 0.77)$ & $\mathrm{ab}$ \\
\hline ITEM 9300 & Italy & 0.65 & $( \pm 0.37)$ & 0.11 & $( \pm 0.06)$ & 0.11 & $( \pm 0.05)$ & 0.87 & $( \pm 0.48)$ & $\mathrm{ab}$ \\
\hline PG 28A & Italy & 1.01 & $( \pm 0.40)$ & 0.22 & $( \pm 0.10)$ & 0.25 & $( \pm 0.08)$ & 1.49 & $( \pm 0.58)$ & $\mathrm{ab}$ \\
\hline ITEM 9318 & Italy & 1.03 & $( \pm 0.68)$ & 0.22 & $( \pm 0.15)$ & 0.35 & $( \pm 0.24)$ & 1.59 & $( \pm 1.07)$ & $\mathrm{ab}$ \\
\hline PG 22A & Italy & 1.67 & $( \pm 1.52)$ & 0.24 & $( \pm 0.23)$ & 0.25 & $( \pm 0.22)$ & 2.16 & $( \pm 1.97)$ & $\mathrm{ab}$ \\
\hline PG 20A & Italy & 2.81 & $( \pm 1.50)$ & 0.66 & $( \pm 0.35)$ & 0.40 & $( \pm 0.16)$ & 3.87 & $( \pm 2)$ & $a b c$ \\
\hline ITEM 9310 & Italy & 6.56 & $( \pm 3.09)$ & 2.46 & $( \pm 1.19)$ & 0.68 & $( \pm 0.29)$ & 9.69 & $( \pm 4.56)$ & abcd \\
\hline PG 5A & Italy & 6.99 & $( \pm 0.89)$ & 2.35 & $( \pm 0.37)$ & 0.85 & $( \pm 0.06)$ & 10.19 & $( \pm 1.27)$ & $\mathrm{cd}$ \\
\hline ITEM 9309 & Italy & 7.70 & $( \pm 3.45)$ & 2.23 & $( \pm 1)$ & 0.80 & $( \pm 0.30)$ & 10.74 & $( \pm 4.74)$ & abcd \\
\hline PG 76A1 & Italy & 8.78 & $( \pm 4.50)$ & 2.32 & $( \pm 1.29)$ & 1.24 & $( \pm 0.60)$ & 12.34 & $( \pm 6.39)$ & abcde \\
\hline PG 30B & Italy & 10.36 & $( \pm 1.25)$ & 2.95 & $( \pm 0.45)$ & 1.26 & $( \pm 0.26)$ & 14.57 & $( \pm 1.92)$ & d \\
\hline ITEM 9329 & Italy & 10.71 & $( \pm 2.32)$ & 3.04 & $( \pm 0.71)$ & 0.84 & $( \pm 0.16)$ & 14.59 & $( \pm 3.16)$ & $\mathrm{cd}$ \\
\hline PG 35A & Italy & 13.30 & $( \pm 6.96)$ & 4.39 & $( \pm 2.26)$ & 1.78 & $( \pm 0.80)$ & 19.47 & $( \pm 10)$ & abcde \\
\hline PG 58A1 & Italy & 19.39 & $( \pm 5.28)$ & 7.51 & $( \pm 1.73)$ & 2.16 & $( \pm 0.15)$ & 29.07 & $( \pm 7.05)$ & abcde \\
\hline ITEM 10027 & Italy & 23.64 & $( \pm 1.57)$ & 7.22 & $( \pm 0.44)$ & 2.49 & $( \pm 0.05)$ & 33.35 & $( \pm 1.99)$ & $\mathrm{e}$ \\
\hline PG 36B & Italy & 23.87 & $( \pm 0.44)$ & 5.63 & $( \pm 1.56)$ & 4.23 & $( \pm 0.19)$ & 33.73 & $( \pm 1.49)$ & e \\
\hline 03-2/A & Spain & 0.24 & $( \pm 0.17)$ & nd & - & nd & - & 0.24 & $( \pm 0.17)$ & \\
\hline FVMM 3-2 & Spain & 0.78 & $( \pm 0.29)$ & 0.03 & $( \pm 0.03)$ & 0.01 & $( \pm 0.01)$ & 0.82 & $( \pm 0.33)$ & $\mathrm{a}$ \\
\hline C1-2 SEV & Spain & 2.24 & $( \pm 1.19)$ & 0.53 & $( \pm 0.42)$ & 0.01 & - & 2.77 & $( \pm 1.61)$ & $\mathrm{ab}$ \\
\hline FVMM 2-1 & Spain & 2.60 & $( \pm 1.60)$ & 0.55 & $( \pm 0.46)$ & 0.24 & $( \pm 0.13)$ & 3.38 & $( \pm 2.17)$ & $\mathrm{ab}$ \\
\hline FVMM AD 2-4 & Spain & 6.38 & $( \pm 3.28)$ & 1.61 & $( \pm 0.91)$ & 0.20 & $( \pm 0.05)$ & 8.19 & $( \pm 4.19)$ & $a b$ \\
\hline 03-5/B SEV.1 & Spain & 6.63 & $( \pm 1.08)$ & 1.31 & $( \pm 0.31)$ & 0.31 & $( \pm 0.05)$ & 8.24 & $( \pm 1.43)$ & $\mathrm{b}$ \\
\hline 03-5/B SEV & Spain & 7.70 & $( \pm 3.57)$ & 1.81 & $( \pm 0.92)$ & 1.06 & $( \pm 0.66)$ & 10.57 & $( \pm 5.01)$ & $a b$ \\
\hline FVMM 1-1 & Spain & 15.63 & $( \pm 4.19)$ & 4.68 & $( \pm 1.25)$ & 1.77 & $( \pm 0.33)$ & 22.08 & $( \pm 5.74)$ & $\mathrm{ab}$ \\
\hline $0-C-1-32 / 2$ & Spain & 56.12 & $( \pm 5.31)$ & 10.67 & $( \pm 1.35)$ & 3.04 & $( \pm 0.21)$ & 69.84 & $( \pm 6.57)$ & $\mathrm{c}$ \\
\hline M16 & Tunisia & nd & - & nd & - & nd & - & nd & - & - \\
\hline M11 & Tunisia & 0.29 & $( \pm 0.07)$ & 0.04 & $( \pm 0.02)$ & nd & - & 0.33 & $( \pm 0.09)$ & $\mathrm{a}$ \\
\hline M19 & Tunisia & 0.30 & $( \pm 0.07)$ & 0.03 & $( \pm 0.02)$ & 0.11 & $( \pm 0.03)$ & 0.45 & $( \pm 0.11)$ & $\mathrm{a}$ \\
\hline M12 & Tunisia & 0.56 & $( \pm 0.23)$ & 0.12 & $( \pm 0.05)$ & 0.06 & $( \pm 0.02)$ & 0.74 & $( \pm 0.30)$ & $\mathrm{ab}$ \\
\hline M15 & Tunisia & 0.47 & $( \pm 0.17)$ & 0.06 & $( \pm 0.02)$ & 0.27 & $( \pm 0.08)$ & 0.80 & $( \pm 0.28)$ & $\mathrm{ab}$ \\
\hline M20 & Tunisia & 0.92 & $( \pm 0.13)$ & nd & - & 0.01 & - & 0.93 & $( \pm 0.13)$ & $\mathrm{b}$ \\
\hline M17 & Tunisia & 0.91 & $( \pm 0.21)$ & 0.12 & $( \pm 0.03)$ & 0.55 & $( \pm 0.12)$ & 1.58 & $( \pm 0.36)$ & $\mathrm{ab}$ \\
\hline M5 & Tunisia & 2.55 & $( \pm 1.43)$ & 0.27 & $( \pm 0.26)$ & nd & - & 2.83 & $( \pm 1.69)$ & $a b$ \\
\hline M2 & Tunisia & 3.21 & $( \pm 1.32)$ & 0.61 & $( \pm 0.31)$ & 0.01 & - & 3.82 & $( \pm 1.63)$ & $a b$ \\
\hline M8 & Tunisia & 3.53 & $( \pm 1.80)$ & 1.01 & $( \pm 0.58)$ & 0.01 & - & 4.55 & $( \pm 2.39)$ & $a b c$ \\
\hline M7 & Tunisia & 3.80 & $( \pm 3.05)$ & 0.77 & $( \pm 0.75)$ & 0.40 & $( \pm 0.32)$ & 4.97 & $( \pm 4.11)$ & $a b c$ \\
\hline M22 & Tunisia & 6.85 & $( \pm 3.59)$ & 1.15 & $( \pm 0.40)$ & 2.07 & $( \pm 0.47)$ & 10.07 & $( \pm 4.45)$ & $a b c$ \\
\hline M21 & Tunisia & 7.10 & $( \pm 4.93)$ & 1.47 & $( \pm 1.24)$ & 1.72 & $( \pm 1.09)$ & 10.29 & $( \pm 7.24)$ & $a b c$ \\
\hline M1 & Tunisia & 8.82 & $( \pm 1.28)$ & 2.16 & $( \pm 0.35)$ & 0.68 & $( \pm 0.23)$ & 11.66 & $( \pm 1.81)$ & c \\
\hline M14 & Tunisia & 10.50 & $( \pm 0.10)$ & 1.72 & $( \pm 0.12)$ & 1.07 & $( \pm 0.10)$ & 13.28 & $( \pm 0.18)$ & c \\
\hline M10 & Tunisia & 11.07 & $( \pm 1.71)$ & 2.48 & $( \pm 0.55)$ & 0.04 & $( \pm 0.03)$ & 13.59 & $( \pm 2.23)$ & c \\
\hline
\end{tabular}


Table 1. Cont.

\begin{tabular}{|c|c|c|c|c|c|c|c|c|c|c|}
\hline \multirow{3}{*}{$\begin{array}{c}\text { Strain ID } \\
\text { F2 }\end{array}$} & \multirow{3}{*}{$\begin{array}{l}\text { Origin } \\
\text { Egypt }\end{array}$} & \multicolumn{9}{|c|}{ Fumonisin Production $(\mu \mathrm{g} / \mathrm{g})$ * } \\
\hline & & \multicolumn{2}{|c|}{ Fumonisin $B_{1}$} & \multicolumn{2}{|c|}{ Fumonisin $\mathbf{B}_{2}$} & \multicolumn{2}{|c|}{ Fumonisin $B_{3}$} & \multicolumn{3}{|c|}{ Total Fumonisins $* *, \S$} \\
\hline & & nd & - & nd & - & nd & - & nd & - & - \\
\hline F6 & Egypt & nd & - & nd & - & nd & - & nd & - & - \\
\hline F7 & Egypt & nd & - & nd & - & nd & - & nd & - & - \\
\hline F10 & Egypt & nd & - & nd & - & nd & - & nd & - & - \\
\hline F12 & Egypt & nd & - & nd & - & nd & - & nd & - & - \\
\hline F19 & Egypt & nd & - & nd & - & nd & - & nd & - & - \\
\hline F22 & Egypt & nd & - & nd & - & nd & - & nd & - & - \\
\hline F23 & Egypt & nd & - & nd & - & nd & - & nd & - & - \\
\hline F25 & Egypt & nd & - & nd & - & nd & - & nd & - & - \\
\hline F26 & Egypt & nd & - & nd & - & nd & - & nd & - & - \\
\hline $\mathrm{F} 27$ & Egypt & nd & - & nd & - & nd & - & nd & - & - \\
\hline F30 & Egypt & nd & - & nd & - & nd & - & nd & - & - \\
\hline F36 & Egypt & nd & - & nd & - & nd & - & nd & - & - \\
\hline F38 & Egypt & nd & - & nd & - & nd & - & nd & - & - \\
\hline F41 & Egypt & nd & - & nd & - & nd & - & nd & - & - \\
\hline F39 & Egypt & 0.22 & $( \pm 0.02)$ & nd & - & nd & - & 0.22 & $( \pm 0.02)$ & a \\
\hline F29 & Egypt & 0.81 & $( \pm 0.05)$ & 0.19 & $( \pm 0.04)$ & 0.12 & $( \pm 0.03)$ & 1.12 & $( \pm 0.11)$ & $\mathrm{b}$ \\
\hline F8 & Egypt & 0.96 & $( \pm 0.90)$ & 0.34 & $( \pm 0.33)$ & nd & - & 1.29 & $( \pm 1.23)$ & $a b$ \\
\hline $\mathrm{F} 4$ & Egypt & 1.18 & $( \pm 0.08)$ & 0.10 & $( \pm 0.02)$ & 0.08 & - & 1.35 & $( \pm 0.11)$ & $\mathrm{b}$ \\
\hline F28 & Egypt & 1.08 & $( \pm 0.69)$ & 0.21 & $( \pm 0.13)$ & 0.09 & $( \pm 0.05)$ & 1.38 & $( \pm 0.87)$ & $a b$ \\
\hline F9 & Egypt & 1.14 & $( \pm 0.79)$ & 0.15 & $( \pm 0.13)$ & 0.32 & $( \pm 0.25)$ & 1.61 & $( \pm 1.17)$ & $\mathrm{ab}$ \\
\hline F32 & Egypt & 1.11 & $( \pm 0.34)$ & 0.72 & $( \pm 0.27)$ & 0.38 & $( \pm 0.20)$ & 2.21 & $( \pm 0.80)$ & $a b$ \\
\hline F5 & Egypt & 4.10 & $( \pm 2.16)$ & 0.70 & $( \pm 0.40)$ & 0.05 & $( \pm 0.03)$ & 4.85 & $( \pm 2.60)$ & $a b c$ \\
\hline F11 & Egypt & 3.56 & $( \pm 1.88)$ & 0.70 & $( \pm 0.44)$ & 0.58 & $( \pm 0.37)$ & 4.85 & $( \pm 2.68)$ & $a b c$ \\
\hline F17 & Egypt & 4.35 & $( \pm 3.24)$ & 2.03 & $( \pm 1.57)$ & nd & - & 6.38 & $( \pm 4.81)$ & $a b c$ \\
\hline F13 & Egypt & 6.02 & $( \pm 1.45)$ & 0.88 & $( \pm 0.11)$ & 0.33 & $( \pm 0.12)$ & 7.23 & $( \pm 1.67)$ & $a b c$ \\
\hline F15 & Egypt & 6.32 & $( \pm 4.25)$ & 1.29 & $( \pm 0.98)$ & 0.38 & $( \pm 0.22)$ & 7.99 & $( \pm 5.45)$ & $a b c$ \\
\hline F3 & Egypt & 7.52 & $( \pm 0.08)$ & 1.95 & $( \pm 0.15)$ & 1.75 & $( \pm 0.15)$ & 11.23 & $( \pm 0.32)$ & c \\
\hline 35 & Iran & nd & - & nd & - & nd & - & nd & - & - \\
\hline 4 & Iran & 0.03 & $( \pm 0.02)$ & nd & - & nd & - & 0.03 & $( \pm 0.02)$ & $\mathrm{a}$ \\
\hline 25 & Iran & 0.10 & $( \pm 0.02)$ & nd & - & nd & - & 0.10 & $( \pm 0.02)$ & $\mathrm{b}$ \\
\hline 2 & Iran & 0.27 & $( \pm 0.08)$ & nd & - & nd & - & 0.27 & $( \pm 0.08)$ & $a b$ \\
\hline 9 & Iran & 0.47 & $( \pm 0.37)$ & nd & - & nd & - & 0.47 & $( \pm 0.37)$ & $a b$ \\
\hline 18 & Iran & 1.21 & $( \pm 0.25)$ & 0.10 & $( \pm 0.05)$ & 0.09 & $( \pm 0.04)$ & 1.40 & $( \pm 0.35)$ & $a b c$ \\
\hline 39 & Iran & 1.65 & $( \pm 0.45)$ & 0.19 & $( \pm 0.18)$ & 0.42 & $( \pm 0.12)$ & 2.26 & $( \pm 0.73)$ & $a b c$ \\
\hline 56 & Iran & 2.21 & $( \pm 1.12)$ & 0.34 & $( \pm 0.18)$ & 0.30 & $( \pm 0.16)$ & 2.85 & $( \pm 1.42)$ & $a b c$ \\
\hline 1 & Iran & 3.94 & $( \pm 0.76)$ & 0.56 & $( \pm 0.18)$ & 0.22 & $( \pm 0.07)$ & 4.72 & $( \pm 1)$ & $c$ \\
\hline 3 & Iran & 4.48 & $( \pm 1.22)$ & 0.76 & $( \pm 0.22)$ & 0.47 & $( \pm 0.16)$ & 5.71 & $( \pm 1.59)$ & $a b c$ \\
\hline 22 & Iran & 4.61 & $( \pm 1.38)$ & 1.65 & $( \pm 0.53)$ & nd & - & 6.26 & $( \pm 1.91)$ & $a b c$ \\
\hline 16 & Iran & 4.66 & $( \pm 1.63)$ & 1.48 & $( \pm 0.58)$ & 0.40 & $( \pm 0.18)$ & 6.55 & $( \pm 2.39)$ & $a b c$ \\
\hline 5 & Iran & 9.92 & $( \pm 5.52)$ & 2.15 & $( \pm 1.35)$ & 1.17 & $( \pm 0.71)$ & 13.25 & $( \pm 7.59)$ & abcd \\
\hline 7 & Iran & 13.65 & $( \pm 4.74)$ & 3.23 & $( \pm 1.15)$ & 1.45 & $( \pm 0.50)$ & 18.33 & $( \pm 6.40)$ & abcd \\
\hline 89 & Iran & 30.81 & $( \pm 4.39)$ & 7.23 & $( \pm 1.01)$ & 1.75 & $( \pm 0.28)$ & 39.79 & $( \pm 5.25)$ & $\mathrm{d}$ \\
\hline
\end{tabular}

* values represent the average $\left( \pm\right.$ SE) of three biological replicates. ${ }^{* *}$ sum of fumonisin $B_{1}$, fumonisin $B_{2}$ and fumonisin $B_{3} .{ }^{\dagger}$ nd: not detected $\left(<0.002 \mu \mathrm{g} / \mathrm{g}\right.$ for fumonisin $B_{1}$ and $<0.001 \mu \mathrm{g} / \mathrm{g}$ for fumonisin $B_{2}$ and fumonisin $\left.B_{3}\right)$. $\S$ within the same country of origin, means followed by different letters are significantly different $(p<0.05)$.

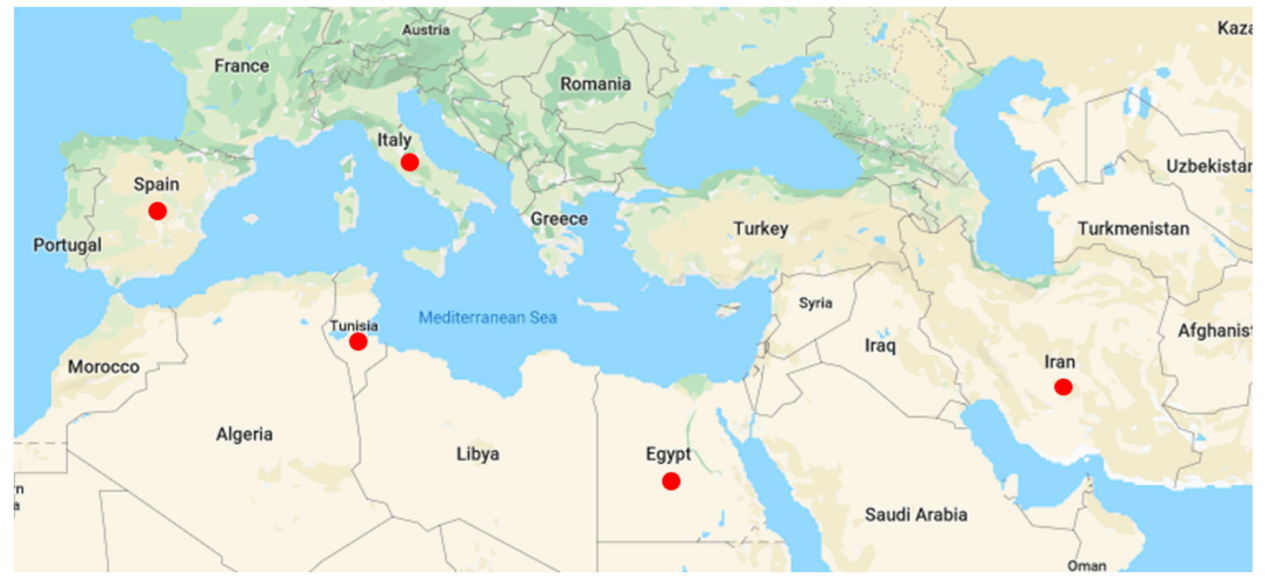

Figure 1. Countries of origin (red dots) of the Fusarium verticillioides strains used in this study. Map downloaded from www.google.com/maps and modified by the authors. 


\subsection{Confirmation of F. verticillioides Identity by PCR Assays}

To preliminarily confirm the identity of the $90 \mathrm{~F}$. verticillioides strains used in this study, species-specific PCR assays were conducted. All strains were grown on Potato Dextrose Agar (PDA (Biolife Italiana, Milan, Italy)) at $22{ }^{\circ} \mathrm{C}$ for $14 \mathrm{~d}$ in the dark. DNA was extracted as described by Beccari et al. [56,57]. PCR assays were carried out with the specific primers VERT1 (GTCAGAATCCATGCCAGAACG) and VERT2 (CACCCGCAGCAATCCATCAG) [58]. A single PCR protocol was optimized using a total reaction of $20 \mu \mathrm{L}$. Each reaction contained $9.2 \mu \mathrm{L}$ of sterile water for molecular biology (5prime, Hilden, Germany), $1.5 \mu \mathrm{L}$ of cresol red (Sigma-Aldrich, Saint Louis, MO, USA), $2 \mu \mathrm{L}$ of 10X PCR buffer (Microtech, Pozzuoli, Naples, Italy), 1.2 $\mu \mathrm{L}$ of magnesium chloride (Microtech), $2 \mu \mathrm{L}$ of $10 \mathrm{mM}$ DNTP mix (Microtech), $1 \mu \mathrm{L}$ of $10 \mu \mathrm{M}$ forward and reverse primers, 0.1 $\mu \mathrm{L}$ of $5 \mathrm{U} / \mu \mathrm{L}$ Taq polymerase (Microtech) and $2 \mu \mathrm{L}$ of template DNA. The PCR cycle consisted of an initial denaturation step at $94{ }^{\circ} \mathrm{C}$ for $2 \mathrm{~min}$, followed by 30 cycles of denaturation $\left(94{ }^{\circ} \mathrm{C}\right.$ for $\left.35 \mathrm{~s}\right)$, annealing $\left(60^{\circ} \mathrm{C}\right.$ for $\left.30 \mathrm{~s}\right)$, extension $\left(72{ }^{\circ} \mathrm{C}\right.$ for $2 \mathrm{~min}$ ) and a final extension at $72{ }^{\circ} \mathrm{C}$ for $5 \mathrm{~min}$. PCR assays contained a positive control (template DNA of $F$. verticillioides) and a negative control with no DNA added. The amplification was performed in a T-100 thermal cycler (Bio Rad, Hercules, CA, USA). All PCR fragments were separated by electrophoresis by applying a tension of $110 \mathrm{~V}$ for about $1 \mathrm{~h}$. Electrophoretic runs were visualized using an UV Image analyzer (Euroclone, Pero, Milan, Italy).

\subsection{Determiantion of Fumonisin Biosynthesis by F. verticillioides In Vitro}

\subsubsection{F. verticillioides Cultures}

To determine in vitro fumonisin biosynthesis, cultures of $F$. verticillioides strains were obtained following the protocol indicated by Covarelli et al. [50] with slight modifications. In brief, $15 \mathrm{~g}$ of finely ground maize grains and $15 \mathrm{~mL}$ of deionized sterile water were added into $100 \mathrm{~mL}$ glass flasks (Duran, Mainz, Germany) to obtain the right moisture for allowing fungal development and then autoclaved three times at alternate days. Three flasks (replicates) for each F. verticillioides strain were then inoculated with a mycelium plug $(0.6 \mathrm{~cm}$ diameter) taken from the growing edge of one-week-old pure fungal cultures of each strain developed on PDA at $22{ }^{\circ} \mathrm{C}$ in the dark. Three flasks (replicates) were used as controls by adding only a PDA plug. Flasks were incubated in the dark at $22{ }^{\circ} \mathrm{C}$ for $4 \mathrm{w}$, and developed cultures were then freeze-dried for $24 \mathrm{~h}$ using a lyophilizer instrument (Heto Powder Dry LL3000, Thermo Fisher Scientific, Waltham, MA, USA), ground with mortar and pestle and stored at $-80^{\circ} \mathrm{C}$ until further analysis.

\subsubsection{Fumonisin Extraction and LC-MS/MS Analysis}

Each fungal culture was extracted and analyzed in triplicate according to the validated and routine procedure also described by Covarelli et al. [50] with slight modifications. In brief, $1 \mathrm{~g}$ of ground sample was extracted with $5 \mathrm{~mL}$ of methanol/water $(75: 25, v / v)$ following $60 \mathrm{~min}$ shaking. The extract was filtered through filter paper. Prior to liquid chromatography, tandem Mass Spectrometry (LC-MS/MS) analysis, the extract was diluted by default 1:50 with a mixture of methanol/water (60:40), then filtered through $0.45 \mu \mathrm{m}$ syringe filter. Twenty microliters were injected into the LC-MS/MS apparatus. If fumonisin levels were out of the calibration range, a further dilution (1:500 or 1:5000) was applied to the raw extract and then re-analyzed.

LC-MS/MS analyses were performed on a QTrap MS/MS system, from Applied Biosystems (Foster City, CA, USA), equipped with an Electrospray Ionization (ESI) interface and a 1100 series micro-Liquid Chromatography system comprising a binary pump and a micro-autosampler from Agilent Technologies (Waldbronn, Germany). The analytical column was a Gemini ${ }^{\circledR}$ C18 column (150 $\times 2 \mathrm{~mm}, 5 \mu \mathrm{m}$ particles) (Phenomenex, Torrance, CA, USA), preceded by a Gemini ${ }^{\circledR} \mathrm{C} 18$ guard column $\left(4 \times 2 \mathrm{~mm}, 5 \mu \mathrm{m}\right.$ particles). The column oven was set at $40^{\circ} \mathrm{C}$. The flow rate of the mobile phase was $200 \mu \mathrm{L} / \mathrm{min}$, and the injection volume was $20 \mu \mathrm{L}$. 
The column effluent was directly transferred into the ESI interface, without splitting. Eluent A was water and eluent $\mathrm{B}$ was methanol, both containing $0.5 \%$ acetic acid. A gradient elution was performed as follows. The percentage of eluent B was increased from $40 \%$ to $80 \%$ in $10 \mathrm{~min}$, kept constant $3 \mathrm{~min}$, then increased to $100 \%$ in $1 \mathrm{~min}$, and kept constant for $4 \mathrm{~min}$. The column was re-equilibrated with $40 \%$ eluent B for $7 \mathrm{~min}$. The ESI interface was used in positive ion mode with the following settings: temperature $350{ }^{\circ} \mathrm{C}$; curtain gas, nitrogen, $30 \mathrm{psi}$; nebulizer gas, air, $10 \mathrm{psi}$; heater gas, air, $30 \mathrm{psi}$; ion spray voltage $+4500 \mathrm{~V}$. The mass spectrometer operated in Multiple Reaction Monitoring (MRM) mode. Mycotoxin quantification was performed by external calibration in neat solvent. The identity of fumonisins was confirmed by comparison with the analytical standard considering chromatography retention time and MRM transitions (ion ratios) in agreement with the official guidelines for mycotoxin identification by Mass Spectrometry [59]. Detection limits in maize fungal cultures were $0.002 \mu \mathrm{g} / \mathrm{g}$ for $\mathrm{FB}_{1}$ and $0.001 \mu \mathrm{g} / \mathrm{g}$ for $\mathrm{FB}_{2}$ and $\mathrm{FB}_{3}$.

Methanol (HPLC grade) and glacial acetic acid were purchased from Mallinckrodt Baker (Milan, Italy). Ultrapure water was produced by a Millipore Milli-Q system (Millipore, Bedford, MA, USA). Filter papers (Whatman no. 4) were obtained from Whatman International Ltd. (Maidstone, UK). HPLC syringe filters (regenerated cellulose, $0.45 \mu \mathrm{m}$ ) were from Alltech (Deerfield, IL, USA).

\subsection{Genetic Structure of Different F. verticillioides Populations}

For genetic diversity assessment, all F. verticillioides strains were cultured on PDA for $7 \mathrm{~d}$. Mycelia were harvested, homogenized in liquid nitrogen, and genomic DNA was extracted using the method already described by Stepień et al. [60]. A pre-validated FUM1-specific marker that showed intraspecific polymorphism in F. verticillioides and F. proliferatum in previous studies $[61,62]$ was used. Briefly, Fum1F1 (CACATCTGTGGGCGATCC)/Fum1R2 (ATATGGCCCCAGCTGCATA) primers were used for FUM1 gene fragment PCR-based amplification and sequencing according to Waśkiewicz et al. [61]. Additionally, FUM6-FUM7 and FUM7-FUM8 intergenic regions were amplified using the primers Fum6eF (AGATTTCCCAACAGTGGCAG)/Fum7bR (GTTTGCTTGGTGGAACTGGT) and Fum7eF (ATCCGGTTGAGTTGGACAAG)/Fum8eR (GGAACAGATGCCCATACCAT) according to Stępień et al. [47].

The BigDye Terminator kit v. 3.1 (Life Technologies, Carlsbad, CA, USA) was used for fluorescent labeling according to the manufacturer's instructions. DNA fragments were purified using alkaline phosphatase and exonuclease I (Thermo Fisher Scientific)) and precipitated using ice-cold 96\% ethanol (Sigma Aldrich, St. Louis, MO, USA). Sequence reading was performed using Applied Biosystems equipment. Sequence reads were analyzed using BioEdit software [63] and aligned using MEGA5 software package [64] using Maximum Parsimony heuristics with standard settings. Based on FUM1 sequences, the most parsimonious tree was calculated (bootstrap test with 1000 replications).

Sequences were compared to the NCBI GenBank-deposited sequence (FUM cluster NCBI (AF155733)) and, in addition, a total of five F. verticillioides FUM1 sequences (F.v.F1.8.I.I, F.v.10I3 (Pisum sativum, Wiatrowo, Poland); F.v.KF3477, F.v.F1M1.1 (Z. mays, Poland); F.v.KF3537 (Ananas comosus, Costa Rica)) were used as references. A total of four Fusarium proliferatum FUM1 sequences (15 F. proliferatum (Z. mays, Iran); F. proliferatum Gar3.2, Gar1 and Gar3.0 (Allium sativum, Poznan, Poland)) were used as outgroup.

\subsection{Statistical Analysis}

To analyze the in vitro fumonisin biosynthesis within each country of origin, total fumonisin content was submitted to ANOVA by allowing a different standard deviation per strain to comply with heteroscedasticity. Generalized least-squares were used for model fitting, as implemented in the gls() function of the nlme package [65] within the R statistical environment [66]. Heteroscedastic Welch's $t$-tests were used for pairwise comparisons of strains, within country [67]. 


\section{Results}

\subsection{Identity Confirmation of F. verticillioides}

DNA extracted from the $90 \mathrm{~F}$. verticillioides strains was subject to PCR assays using the species-specific primer pair VERT1/VERT2. As expected, a single fragment of $800 \mathrm{bp}$ amplified in all the samples, thus confirming their identity as F. verticillioides.

\subsection{Fumonisin Biosynthesis by F. verticillioides In Vitro}

Data on the in vitro biosynthesis of $\mathrm{FB}_{1}, \mathrm{FB}_{2}$ and $\mathrm{FB}_{3}$ with the calculation of total fumonisins (sum of $\mathrm{FB}_{1}, \mathrm{FB}_{2}$ and $\mathrm{FB}_{3}$ ) by the 90 F. verticillioides strains are summarized in Table 1.

In general, this analysis revealed that $80 \%(n=71)$ of the F. verticillioides strains investigated in this study were able to produce fumonisins at variable levels, while the remaining $20 \%(n=19)$ showed undetectable levels (not detected; nd) of fumonisins and were considered, in this experimental condition, as non-producing strains.

Total fumonisins biosynthesized by all positive strains $(n=71)$ varied from 0.03 to $69.84 \mu \mathrm{g} / \mathrm{g}$ (average $7.88 \mu \mathrm{g} / \mathrm{g}$ ), with $\mathrm{FB}_{1}$ being the most abundant analogue followed by $\mathrm{FB}_{2}$ and $\mathrm{FB}_{3}$. All positive strains $(100 \%, n=71)$ produced $\mathrm{FB}_{1}$ in levels ranging from $0.03-56.12 \mu \mathrm{g} / \mathrm{g}$ (average $5.9 \mu \mathrm{g} / \mathrm{g}$ ), while 64 of 71 strains $(90 \%)$ produced $\mathrm{FB}_{2}$ in levels ranging from $0.03-10.67 \mu \mathrm{g} / \mathrm{g}$ (average $1.6 \mu \mathrm{g} / \mathrm{g}$ ). Finally, 59 of 71 strains $\left(83 \%\right.$ ) biosynthesized $\mathrm{FB}_{3}$ in a range from $0.01-4.23 \mu \mathrm{g} / \mathrm{g}$ (average $0.7 \mu \mathrm{g} / \mathrm{g}$ ). The average ratios of $\mathrm{FB}_{1}$ :total fumonisins, $\mathrm{FB}_{2}$ :total fumonisins and $\mathrm{FB}_{3}$ :total fumonisins were $0.77,0.13$ and 0.05 , respectively. The three fumonisin analogues analyzed in this study $\left(\mathrm{FB}_{1}, \mathrm{FB}_{2}\right.$ and $\left.\mathrm{FB}_{3}\right)$ were simultaneously produced by $81 \%$ of positive strains $(n=58)$, while two analogues, $\mathrm{FB}_{1}$ and $\mathrm{FB}_{2}$ as well as $\mathrm{FB}_{1}$ and $\mathrm{FB}_{3}$, were simultaneously biosynthesized by $7 \%(n=5)$ and $1 \%(n=1)$ of positive strains, respectively. Finally, 7 out of 71 strains $(10 \%)$ producerd only $\mathrm{FB}_{1}$. No strains biosynthesized $\mathrm{FB}_{2}$ or $\mathrm{FB}_{3}$ only.

In most cases, considering all producing strains $(n=71)$, differences in fumonisin production were detected among the strains isolated in the same country.

In detail, 20 out of 22 strains (91\%; Figure 2) isolated from maize grains in Italy and analyzed in this study showed the ability to biosynthesize fumonisins in variable levels (Table 1). Total fumonisins biosynthesized by the Italian positive strains $(n=20)$ varied from 0.03 to $33.73 \mu \mathrm{g} / \mathrm{g}$ (average 9.98 $\mu \mathrm{g} / \mathrm{g})$. All fumonisin-producing Italian strains $(100 \%, n=20)$ biosynthesized $\mathrm{FB}_{1}$ in levels ranging from $0.03-23.87 \mu \mathrm{g} / \mathrm{g}$ (average $5.7 \mu \mathrm{g} / \mathrm{g}$ ), while 19 out of 20 strains $(95 \%)$ produced $\mathrm{FB}_{2}$ and $\mathrm{FB}_{3}$ in levels ranging from $0.03-5.63 \mu \mathrm{g} / \mathrm{g}$ (average $2.20 \mu \mathrm{g} / \mathrm{g}$ ) and $0.05-4.23 \mu \mathrm{g} / \mathrm{g}$ (average $0.94 \mu \mathrm{g} / \mathrm{g}$ ), respectively. The average ratios of $\mathrm{FB}_{1}$ :total fumonisins, $\mathrm{FB}_{2}$ :total fumonisins and $\mathrm{FB}_{3}$ :total fumonisins were 0.71 , 0.18 and 0.10 , respectively. The three fumonisin analogues $\left(\mathrm{FB}_{1}, \mathrm{FB}_{2}\right.$ and $\left.\mathrm{FB}_{3}\right)$ were simultaneously produced by $95 \%$ of positive Italian strains $(n=20)$, while 1 out of 20 strains $(5 \%)$ produced only $\mathrm{FB}_{1}$. Strains ITEM 10027 and PG 36B showed a significantly higher biosynthesis of total fumonisins with respect to the other Italian strains $(p<0.02)$, with the exception of strains PG 58A1, PG 35A and PG 76A1 $(p>0.07)$.

Considering the Spanish strains analyzed in this study, all of them $(100 \%, n=9$; Figure 2$)$ were able to in vitro biosynthesize different levels of fumonisins. Total fumonisins produced by these strains ranged from 0.24 to $69.84 \mu \mathrm{g} / \mathrm{g}$ (average $14.01 \mu \mathrm{g} / \mathrm{g}$ ) with $\mathrm{FB}_{1}$ being the most abundant (range 0.24-56.12 $\mu \mathrm{g} / \mathrm{g}$; average $10.9 \mu \mathrm{g} / \mathrm{g}$ ), followed by $\mathrm{FB}_{2}$ (range $0.03-10.67 \mu \mathrm{g} / \mathrm{g}$; average $2.4 \mu \mathrm{g} / \mathrm{g}$ ) and $\mathrm{FB}_{3}$ (range 0.01-3.04 $\mu \mathrm{g} / \mathrm{g}$; average $0.7 \mu \mathrm{g} / \mathrm{g}$ ). The average ratios of $\mathrm{FB}_{1}$ :total fumonisins, $\mathrm{FB}_{2}$ :total fumonisins and $\mathrm{FB}_{3}$ :total fumonisins were $0.81,0.15$ and 0.04 , respectively. Eight out of 9 strains (89\%) simultaneously biosynthesized all three fumonisin analogues, while in 1 out of 9 strains $(11 \%)$ only $\mathrm{FB}_{1}$ was detected. Strain $0-C-1-32 / 2$ showed a significantly higher $(p<0.008)$ production of total fumonisins with respect to the other Spanish strains analyzed in this study. 
$\square$ Fumonisin producers $\quad \square$ Fumonisin non-producers

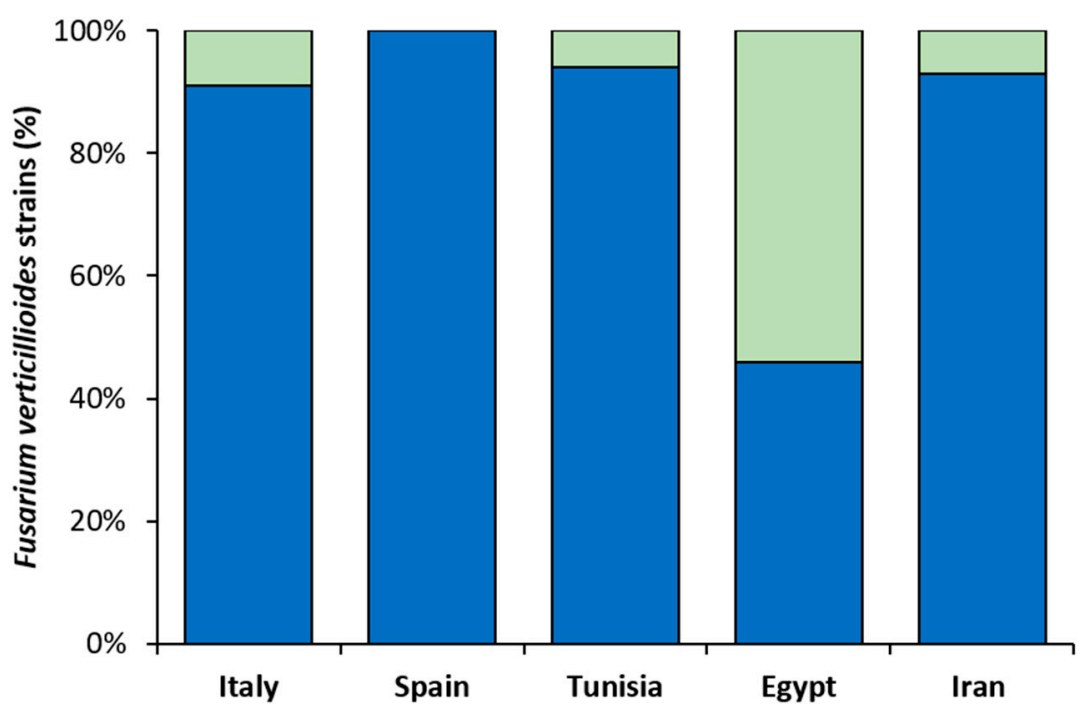

Figure 2. Fusarium verticillioides strains (\%) isolated from maize kernels harvested in five Mediterranean countries that showed in vitro production of detectable (fumonisin producers) and non-detectable levels (fumonisin non-producers) of total fumonisins. Italy, $n=22$; Spain, $n=9$; Tunisia, $n=16$; Egypt, $n=28$; Iran, $n=15$.

Focusing on the Tunisian strains analyzed in this study, 15 out of 16 strains (94\%; Figure 2) produced detectable amounts of fumonisins in vitro. Total fumonisin levels ranged from 0.33 to 13.59 $\mu \mathrm{g} / \mathrm{g}$, with an average production equal to $5.36 \mu \mathrm{g} / \mathrm{g}$. Twelve out of 15 strains $(80 \%)$ biosynthesized all the analogues, while 2 out of 15 strains (13\%) produced $\mathrm{FB}_{1}$ and $\mathrm{FB}_{2}$, and the remaining strain $(7 \%$; $n=1$ ) produced $\mathrm{FB}_{1}$ and $\mathrm{FB}_{3}$. The gradient of production did not differ from that detected for the other strains: $\mathrm{FB}_{1}$ (average $4.01 \mu \mathrm{g} / \mathrm{g}$ ) $>\mathrm{FB}_{2}$ (average $0.86 \mu \mathrm{g} / \mathrm{g}$ ) $>\mathrm{FB}_{3}$ (average $0.54 \mu \mathrm{g} / \mathrm{g}$ ). The average ratios of $\mathrm{FB}_{1}$ :total fumonisins, $\mathrm{FB}_{2}$ :total fumonisins and $\mathrm{FB}_{3}$ :total fumonisins were $0.76,0.13$ and 0.11 , respectively. Strains M10, M14 and M1 showed significantly higher total fumonisin biosynthesis with respect to the other Tunisian strains $(p<0.02)$, with the exception of strains M21, M22, M7 and M8 $(p>0.05)$.

The F. verticillioides population isolated from maize kernels in Egypt and analyzed in this study showed a low percentage of fumonisin-producing strains $(46 \%, n=13$; Figure 2$)$ with an average total fumonisin production of $3.98 \mu \mathrm{g} / \mathrm{g}$ (range $0.22-11.23 \mu \mathrm{g} / \mathrm{g}$ ). All producing strains biosynthesized $\mathrm{FB}_{1}$ (range $0.22-7.52 \mu \mathrm{g} / \mathrm{g}$; average $2.95 \mu \mathrm{g} / \mathrm{g}$ ), while 12 out of 13 strains $(92 \%$; average $0.77 \mu \mathrm{g} / \mathrm{g}$ ) and 10 out of 13 strains $\left(77 \%\right.$; average $0.40 \mu \mathrm{g} / \mathrm{g}$ ) showed the ability to biosynthesize $\mathrm{FB}_{2}$ and $\mathrm{FB}_{3}$, respectively. In other words, $77 \%$ of producing strains were able to simultaneously produce all three fumonisin analogues, while $15 \%(n=2)$ and $8 \%(n=1)$ of the Egyptian strains showed the ability to biosynthesize $\mathrm{FB}_{1}$ and $\mathrm{FB}_{2}$ or $\mathrm{FB}_{1}$ alone, respectively. The average ratios of $\mathrm{FB}_{1}$ : total fumonisins, $\mathrm{FB}_{2}$ :total fumonisins and $\mathrm{FB}_{3}$ :total fumonisins were $0.76,0.17$ and 0.09 , respectively. The Egyptian strain F3 showed a significantly higher $(p<0.01)$ production of total fumonisins than F39, F29, F8, F4, F28, F9 and F32 strains.

In the F. verticillioides population isolated from maize kernels in Iran and anlyized in this study, a total of 14 fumonisin-producing strains were recovered (93\%; Figure 2). Total fumonisins biosynthesized by all positive strains $(n=14)$ varied from 0.03 to $39.79 \mu \mathrm{g} / \mathrm{g}$ (average $7.28 \mu \mathrm{g} / \mathrm{g}$ ). All producing Iranian strains $(100 \%, n=14)$ biosynthesized $\mathrm{FB}_{1}$ in levels ranging from $0.03-30.81 \mu \mathrm{g} / \mathrm{g}$ (average $5.57 \mu \mathrm{g} / \mathrm{g}$ ), while 11 out of 14 strains $\left(71 \%\right.$ ) produced $\mathrm{FB}_{2}$ in levels ranging from $0.1-7.23 \mu \mathrm{g} / \mathrm{g}$ (average $0.70 \mu \mathrm{g} / \mathrm{g}$ ), and 10 out of 14 strains (64\%) biosynthesized $\mathrm{FB}_{3}$ in levels ranging from $0.09-1.75 \mu \mathrm{g} / \mathrm{g}$ (average 0.70 $\mu \mathrm{g} / \mathrm{g}$ ), respectively. The average ratios of $\mathrm{FB}_{1}$ :total fumonisins, $\mathrm{FB}_{2}$ :total fumonisins and $\mathrm{FB}_{3}$ :total fumonisins were $0.83,0.14$ and 0.07 , respectively. The three fumonisin analogues $\left(\mathrm{FB}_{1}, \mathrm{FB}_{2}\right.$ and $\left.\mathrm{FB}_{3}\right)$ 
were simultaneously produced by $64 \%$ of positive Iranian strains $(n=9)$, while 4 out of 14 strains (29\%) produced only $\mathrm{FB}_{1}$, and 1 out of 14 strains $(7 \%)$ biosynthesized $\mathrm{FB}_{1}$ and $\mathrm{FB}_{2}$. The Iranian strain 89 showed a significantly higher total fumonisin biosynthesis than the other strains from the same country $(p<0.01)$, with the exception of strains 5 and $7(p>0.05)$.

Taking into account all fumonisin-producing strains of each country analyzed in this study, differences in total fumonisin biosynthesis among countries were also detected (Figure 3). In particular, the Spanish strains used in this study showed a significantly higher total fumonisin production (average $14.01 \mu \mathrm{g} / \mathrm{g}$ ) than the Egyptian ones (average $3.98 \mu \mathrm{g} / \mathrm{g})(p=0.02)$. Also, the total fumonisin productions detected for the Italian (average $9.98 \mu \mathrm{g} / \mathrm{g}$ ), Tunisian (average $5.36 \mu \mathrm{g} / \mathrm{g}$ ) and Iranian (average $6.79 \mu \mathrm{g} / \mathrm{g}$ ) strains were higher than the Egyptian ones and lower than the Spanish ones, even if no significant differences were recorded ( $p>0.46$ and $p>0.47$, respectively) (Figure 3 ).

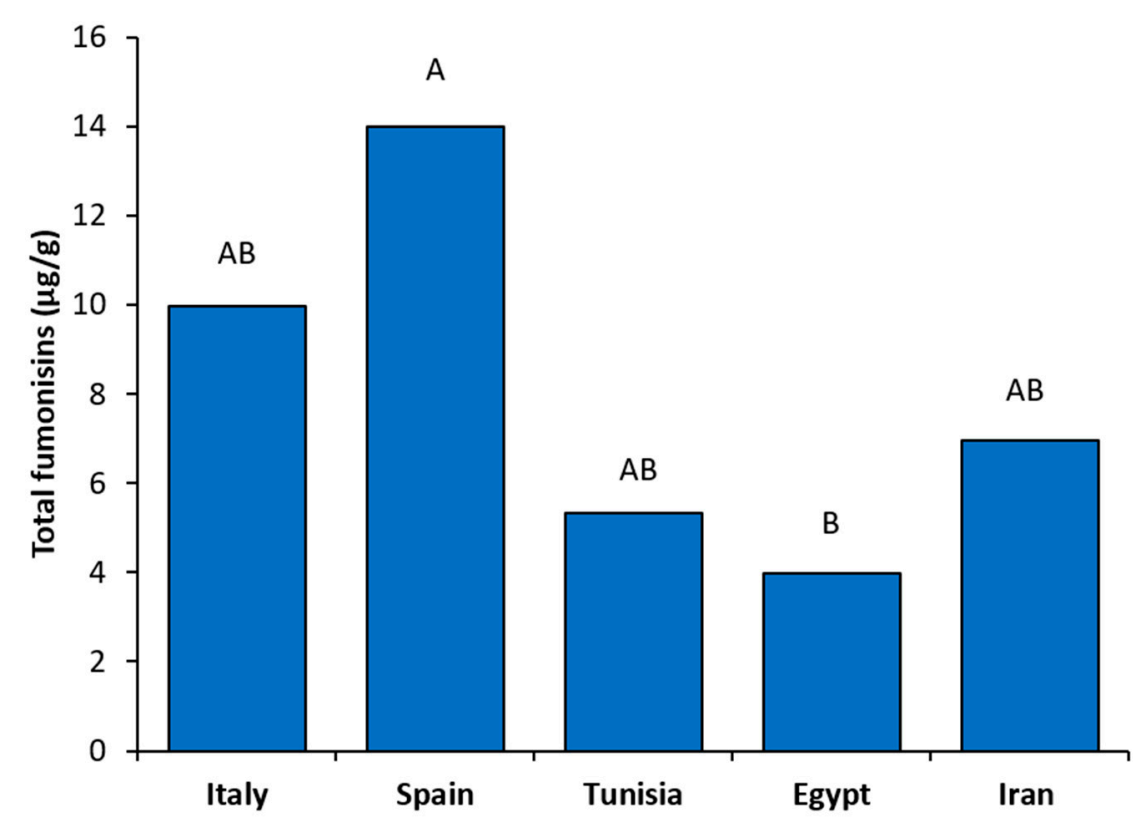

Figure 3. Average of total fumonisins ( $\mu \mathrm{g} / \mathrm{g}$ ) biosynthesized by Fusarium verticillioides fumonisin-producing strains isolated from maize kernels harvested in each of the five countries analyzed in this study. Means with different letters are significantly different $(p<0.05)$.

\subsection{Genetic Structure and Variability of F. verticillioides Populations}

We sequenced a portion of a divergent FUM1 gene to evaluate the diversity among the five populations of $F$. verticillioides originating from various countries. All strains amplified DNA fragments of about 1100 bp in length. Additionally, the FUM6-FUM7 (ca. 550 bp) and FUM7-FUM8 (ca. 500 bp) intergenic regions were sequenced using the primers described previously [47].

The sequences were aligned, the ends trimmed manually using MEGA 5 software, and dendrograms of similarities were calculated. Interestingly, the intergenic regions did not show polymorphisms, which was rather unexpected, since these regions normally accumulated more point mutations than the coding regions. However, this means that the F. verticillioides strains characterized in this study, even if originating from different countries, were basically uniform (results not shown).

Therefore, only slightly more polymorphic FUM1 sequences were analyzed and shown (Figure 4). Apparently, neither geographical origin nor fumonisin production ability were correlated to the genetic diversity of the strain set, as almost all of them grouped together. Only four strains from Egypt (F10, F12, F13 and F36) were distinguished from the remaining strains at a bootstrap value of 60, including our five reference sequences [61] and NCBI GenBank-deposited FUM cluster sequences (AF155773) reported by Proctor et al. [45]. 


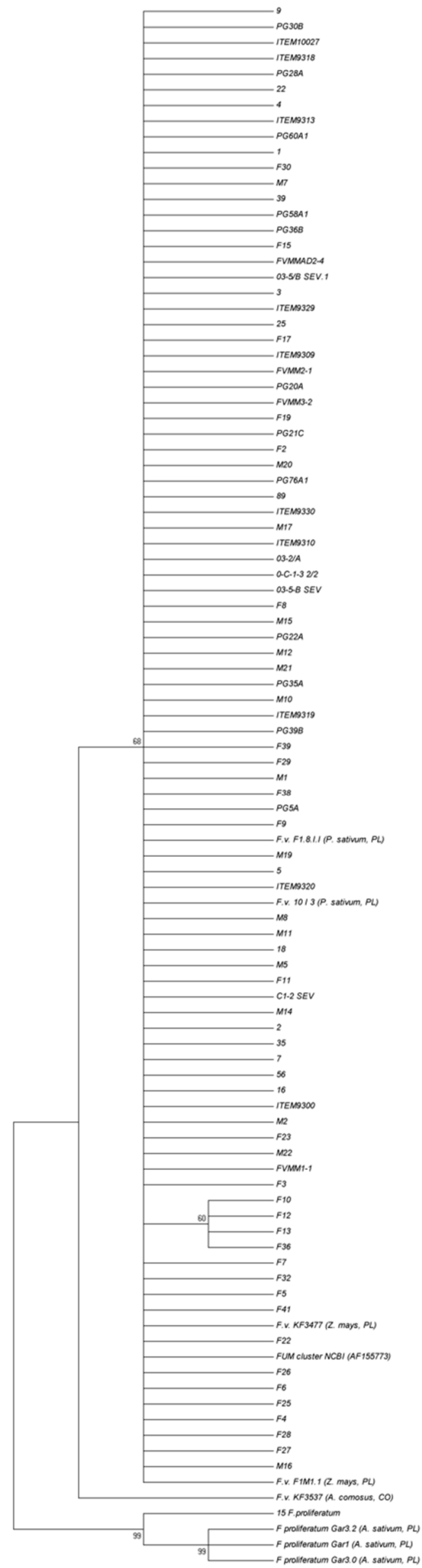

Figure 4. A most parsimonious tree calculated based on the partial FUM1 sequences of 90 Fusarium verticillioides strains isolated from Zea mays of different origins using the maximum parsimony setting, bootstrap set to $50 \%$, and 1000 replications were done. Five reference strains isolated from Pisum sativum (F.v. F1.8.I.I; F.v. 10 I 3), Z. mays (F.v. KF3477; F.v. F1M1.1) and Ananas comosus (F.v. KF3537) were added to the analysis, as well as the NCBI GenBank-deposited FUM cluster sequences (AF155773). Four Fusarium proliferatum sequences were also included as outgroup (15; Gar3.2; Gar1; Gar3.0). 


\section{Discussion}

This study was aimed at investigating the different ability of selected F. verticillioides strains isolated from maize kernels harvested in five Mediterranean countries to in vitro biosynthesize fumonisins as well as at characterizing their genetic structure to assess possible variabilities among them. So far, various studies have been conducted to analyze the ability of different $F$. verticillioides strains from diverse geographic areas to biosynthesize fumonisins. In several investigations, a large percentage of strains able to produce detectable amounts of these mycotoxins were usually found. However, the presence of strains that were not able to biosynthesize measurable levels of fumonisins was also reported. In this research, the majority of the strains isolated from maize grains in Italy, Spain, Tunisia and Iran, analyzed in this study, produced detectable levels of fumonisins $(91 \%, 100 \%, 94 \%$ and $94 \%$ respectively; Figure 2), while the remaining part showed a lack of ability to produce measurable amounts of these mycotoxins. Similar percentages of fumonisin-producing strains $(>80 \%)$ were also detected in other F. verticillioides populations isolated from maize in Croatia [68], Spain [15,69], Italy [50], Iran [22], Egypt [17], Brazil [41,44,49], Korea [70], USA [71], Argentina [55,72] and from durum wheat in Argentina [2].

Conversely, in this study, only $46 \%$ of the analyzed Egyptian strains showed the ability to biosynthesize detectable amounts of fumonisins (Figure 2). Similarly to other studies, low incidences of producing strains were also recorded in other F. verticillioides populations such as those isolated from maize in Croatia (55\%) [73], Taiwan (66\%) [74] and Spain (36\%) [14].

In general, the producing strains analyzed in this study biosynthesized fumonisin analogues following the "typical" gradient: $\mathrm{FB}_{1}>\mathrm{FB}_{2}>\mathrm{FB}_{3}$. A predominance of $\mathrm{FB}_{1}$ compared to the other analyzed fumonisin analogues was recovered also in other F. verticillioides populations such as those isolated from maize in Spain [15,75], Italy [76], Iran [22], Brazil [44,49], Argentina [55,72], Egypt [17], South Korea and South Africa [39]. In this study, no F. verticillioides strains producing more $\mathrm{FB}_{2}$ or $\mathrm{FB}_{3}$ than $\mathrm{FB}_{1}$ were recorded. Conversely, these types of strains were observed in $F$. verticillioides populations isolated from durum wheat in Argentina [2] and from maize and sorghum cultivated in the United States [77].

As known, fumonisin production within the $F$. verticillioides species could quantitatively vary due to the different biosynthetic ability of the different strains [24,40]. Also in this study, variability of fumonisin production among strains isolated in the same country was found, highlighting that mycotoxigenic diversity occurred within the five investigated F. verticillioides populations. Variability among F. verticillioides strains isolated from maize in the same country was commonly detected in many surveys in other parts of the world $[2,8,15,17,22,44,49,55,73-75]$.

Variability in fumonisin production was also recorded among F. verticillioides strains isolated from different countries $[30,39,71]$. Also in this study, differences in fumonisin production among strains of different geographic origin were detected. In particular, the Spanish and Egyptian strains analyzed in this study showed a high level of mycotoxigenic variability, being the populations with the highest and the lowest fumonisin productions, respectively.

Interestingly, these two populations were also those with the highest and lowest percentages of fumonisin-producing (Spain) and non-producing (Egypt) strains. Conversely, the other three investigated populations of $F$. verticillioides (isolated from Italy, Tunisia and Iran) considered in this study did not show a significant variability of fumonisin production. In agreement with the results of Vogelgsang et al. [78], it is important to consider that in vitro results cannot be fully extrapolated to in vivo conditions because there are several factors influencing Fusarium infections and secondary metabolite production in the field. However, in vitro results could provide important information, which may be useful to understand intra-population variability within a single country as well as inter-population variability among different countries.

In this study, the mycotoxigenic characterization of F. verticillioides strains from different geographic origins was coupled to the study of the genetic structure of these populations. The genetic diversity of $F$. verticillioides has been studied using multiple techniques, including AFLP and RAPD methods [50,53,79]. 
Recently, however, direct sequencing of specific genomic regions has become more popular because of its high discrimination power and accuracy. The FUM1 gene has already beeeen proven to be useful to assess species diversity inside the FFSC, serving as a source of phylogenetic and chemotypic markers [47], showing often higher levels of polymorphisms than constitutively expressed genes [e.g., beta tubulin (tub2) or translation elongation factor $1 \alpha$ (tef-1 $\alpha$ )].

Our previous studies suggested there might be high levels of intraspecific genetic uniformity inside F. verticillioides populations, particularly when compared to the high diversity of the closely related species F. proliferatum $[61,62,80,81]$. The use of the FUM1 gene sequence analysis allowed for discrimination of subpopulations likely related to the host species of origin. We assumed that a similar rule would be valid for F. verticillioides; therefore, we added some pea- and pineapple-derived strains to the analysis (Figure 4). It was also possible that geographical differences between populations would become visible.

However, in the present study we could not confirm this hypothesis. In fact, this was in accordance to previous findings, which did not reveal significant differences between F. verticillioides strains from different hosts [61]. This was also confirmed by the sequence analysis of the intergenic regions between FUM6 and FUM7 as well as FUM7 and FUM8 genes (results not shown), which were previously used for polymorphism screening [47]. The most likely explanation for this situation may be the endophytic type of growth observed for this pathogen in maize, which combined with the extensive seed material transfer between countries and continents made the population uniform across the world. Another possibility is that FUM cluster integrity and structure undergoes much more strict selection pressure in F. verticillioides than in F. proliferatum. This may implicate that fumonisin production by F. verticillioides is more essential to complete its life cycle than it is for F. proliferatum. This issue was already reported by Glenn et al. [82] but never confirmed for F. proliferatum.

The only outlier obtained in this study was a group of four strains (F10, F12, F13 and F36) isolated from Egypt (Figure 4), which was distinct from the remaining strains. Only one of these strains (F13) produced fumonisins in detectable amounts (Table 1). They should be further studied to explain their genetic diversity.

\section{Conclusions}

In this study, we analyzed fumonisin production as well as genetic structures of five $F$. verticillioides populations isolated from maize kernels in five Mediterranean countries.

The characterization of a selected number of strains per country does not allow a general conclusion to be drawn at the country level; however, the results obtained in these experimental conditions highlighted:

(i) the presence of an Egyptian population which differed from the others for its low percentage of fumonisin-producing strains;

(ii) the presence of significant differences in fumonisin production within the strains isolated in each of the surveyed countries and, in some cases, also among populations isolated from different countries;

(iii) the high level of genetic uniformity inside the populations analyzed;

(iv) the general absence of correlation between geographical origin and/or fumonisin production ability with the genetic diversity of the strain set;

(v) the presence of four Egyptian strains that were distinguished from the other strains at a bootstrap value of 60 .

Author Contributions: Conceptualization, L.C.; validation, G.B. and Ł.S.; formal analysis, Ł.S., A.O. and V.M.T.L.; investigation, G.B., Ł.S., V.M.T.L., B.C., S.I.A.-E.F., F.V. and M.U.; resources, Ł.S., V.M.T.L. and L.C.; data curation, G.B. and Ł.S.; writing—original draft preparation, G.B.; writing—review and editing, Ł.S., V.M.T.L. and L.C.; visualization, G.B.; supervision, L.C. All authors have read and agree to the published version of the manuscript.

Funding: This research received no external funding. 
Acknowledgments: The authors wish to thank Antonio Moretti (National Research Council, ISPA-CNR, Bari, Italy) for providing the Italian strains from the ITEM collection, Vicente Sanchis (University of Lleida, Spain) for providing the strains from Spain, Souheib Oueslati (Université Libre de Tunis, Tunisia) for providing the strains from Tunisia and Younes Rezaee Danesh (Urmia University, Urmia, Iran) for providing the strains from Iran.

Conflicts of Interest: The authors declare no conflicts of interest.

\section{References}

1. O’Donnell, K.; Nirenberg, H.I.; Aoki, T.; Cigelnik, E. A multigene phylogeny of the Gibberella fujikuroi species complex: detection of additional phylogenetic distinct species. Mycoscience 2000, 41, 61-78. [CrossRef]

2. Palacios, S.A.; Susca, A.; Haidukowski, M.; Stea, G.; Cendoya, E.; Ramírez, M.L.; Chulze, S.N.; Farnochi, M.C.; Moretti, A.; Torres, A.M. Genetic variability and fumonisin production by Fusarium proliferatum isolated from durum wheat grains in Argentina. Int. J. Food Microbiol. 2015, 18, 35-41. [CrossRef]

3. Kvas, M.; Marasas, W.F.O.; Wingfield, B.D.; Wingfield, M.J.; Steenkamp, E.T. Diversity and evolution of Fusarium species in the Gibberella fujikuroi complex. Fungal Divers. 2009, 34, 1-21.

4. Logrieco, A.; Mulè, G.; Moretti, A.; Bottalico, A. Toxigenic Fusarium species and mycotoxins associated with maize ear rot in Europe. Eur. J. Plant Pathol. 2002, 108, 597-609. [CrossRef]

5. Folcher, L.; Jarry, M.; Weissenberger, A.; Gérault, F.; Eychenne, N.; Delos, M.; Regnault-Roger, C. Comparative activity of agrochemical treatments on mycotoxin levels with regard to corn borers and Fusarium mycoflora in maize (Zea mays L.) fields. Crop Prot. 2009, 28, 302-308. [CrossRef]

6. Bottalico, A. Fusarium diseases of cereals: Species complex and related mycotoxins profiles, in Europe. J. Plant Pathol. 1998, 80, 85-103.

7. Oldenburg, E.; Höppner, F.; Ellner, F.; Weinert, J. Fusarium disease of maize associated with mycotoxin contamination of agricultural products intended to be used for food and feed. Mycotoxin Res. 2017, 33, 167-182. [CrossRef]

8. Marín, S.; Ramos, A.J.; Cano-Sancho, G.; Sanchis, V. Reduction of mycotoxins and toxigenic fungi in the Mediterranean basin maize chain. Phytopathol. Mediterr. 2012, 51, 93-118.

9. Fandohan, P.; Hell, K.; Marasas, W.F.O.; Wingfield, M.J. Infection of maize by Fusarium species and contamination with fumonisin in africa. Afr. J. Biotechnol. 2003, 2, 570-579.

10. Mirzadi Gohari, A.M.; Javan-Nikkhah, M.; Hedjaroude, G.A.; Abbasi, M.; Rahjoo, V.; Sedaghat, N. Genetic diversity of Fusarium verticillioides isolates from maize in Iran based on vegetative compatibility grouping. J. Plant Pathol. 2008, 90, 113-116.

11. Covarelli, L.; Beccari, G.; Salvi, S. Infection by mycotoxigenic fungal species and mycotoxin contamination of maize grain in Umbria, central Italy. Food Chem. Toxicol. 2011, 49, 2365-2369. [CrossRef] [PubMed]

12. Venturini, G.; Assante, G.; Vercesi, A. Fusarium verticillioides contamination patterns in northern Italian maize during the growing season. Phytopathologia Mediterr. 2011, 50, 110-120.

13. Lazzaro, I.; Moretti, A.; Giorni, P.; Brera, C.; Battilani, P. Organic vs conventional farming: differences in infection by mycotoxin-producing fungi on maize and wheat in Northern and Central Italy. Crop Prot. 2015, 72, 22-30. [CrossRef]

14. Sala, N.; Sanchis, V.; Vilaro, P.; Viladrich, R.; Torres, M.; Viñas, I.; Canela, R. Fumonisin producing capacity of Fusarium strains isolated from cereals in Spain. J. Food Prot. 1994, 57, 915-917. [CrossRef]

15. Ariño, A.; Juan, T.; Estopañan, G.; González-Cabo, J.F. Natural occurrence of Fusarium species, fumonisin production by toxigenic strains, and concentrations of fumonisins $\mathrm{B}_{1}$ and $\mathrm{B}_{2}$ in conventional and organic maize grown in Spain. J. Food Protect. 2007, 70, 151-156. [CrossRef]

16. Aguín, O.; Cao, A.; Pintos, C.; Santiago, R.; Mansilla, P.; Butrón, A. Occurence of Fusarium species in maize kernels grown in northwestern Spain. Plant Pathol. 2014, 63, 946-951. [CrossRef]

17. Fadl Allah, E.M. Occurrence and toxigenicity of Fusarium moniliforme from freshly harvested maize ears with special references to fumonisin production in Egypt. Mycopathologia 1998, 140, 99-103. [CrossRef]

18. Aboul-Nasr, M.B.; Obied-Allah, M.R.A. Biological and chemical detection of fumonisins produced on agar medium by Fusarium verticillioides isolates collected from corn in Sohag, Egypt. Microbiology 2013, 159, 1720-1724. [CrossRef] 
19. Abd El-Fatah, S.I.; Naguib, M.M.; El-Hossiny, E.N.; Sultan, Y.Y. Occurrence of Fusarium species and the potential accumulation of its toxins in Egyptian maize grains. Int. J. Adv. Res. 2015, 3, 1435-1444.

20. Abd-El Fatah, S.I.; Naguib, M.M.; El-Hossiny, E.N.; Sultan, Y.Y.; Abodalam, T.H.; Yli-Mattila, T. Molecular versus morphological identification of Fusarium spp. isolated from Egyptian corn. Res. J. Pharm. Biol. Chem. Sci. 2015, 6, 1813-1822.

21. Hussien, T.; Carlobos-Lopez, A.L.; Cumagun, C.J.R.; Yli-Mattila, T. Identification and quantification of fumonisin-producing Fusarium species in grain and soil samples from Egypt and the Philippines. Phytopathol. Mediterr. 2017, 56, 146-153.

22. Ghiasian, S.A.; Rezayat, S.M.; Kord-Bacheh, P.; Hossein, M.; Yazdanpanah, H.; Shephard, G.S.; van der Westhuizen, L.; Vismer, H.; Marasas, W.F.O. Fumonisin production by Fusarium species isolated from freshly harvested corn in Iran. Mycopathologia 2005, 159, 31-40. [CrossRef]

23. Gelderblom, W.C.A.; Jaskiewicz, J.; Marasas, W.F.O.; Thiel, P.G.; Horak, R.M.; Vleggar, R.; Kriek, N.P.J. Fumonisins-Novel mycotoxins with cancer-promoting activity produced by Fusarium moniliforme. Appl. Environ. Microbiol. 1988, 54, 1806-1811. [CrossRef]

24. Ferrigo, D.; Raiola, A.; Causin, R. Fusarium toxins in cereals: Occurrence, legislation, factors promoting the appearance and their management. Molecules 2016, 21, 627. [CrossRef]

25. Shephard, G.S.; Marasas, W.F.O.; Leggott, N.L.; Yazdanpanah, H.; Rahimian, H. Natural occurrence of fumonisins in corn from Iran. J. Agric. Food Chem. 2000, 48, 1860-1864. [CrossRef]

26. African Development Bank Group. Annual Core Data. Available online: http://high5.opendataforafrica.org (accessed on 28 June 2018).

27. Food and Agriculture Organization of the United Nations. Statistic Division Database 2014. Available online: http://faostat.fao.org (accessed on 3 January 2018).

28. Lanubile, A.; Maschietto, V.; Borrelli, V.M.; Stagnati, L.; Logrieco, A.F.; Marocco, A. Molecular basis of resistance to Fusarium ear rot in maize. Front. Plant Sci. 2017, 8, 1774. [CrossRef]

29. Marasas, W.F.O. Discovery and occurrence of the fumonisins: A historical perspective. Environ. Health Perspect. 2011, 109, 239-243.

30. Rheeder, J.P.; Marasas, W.O.; Vismer, H.F. Production of fumonisin analogs by Fusarium species. Appl. Environ. Microbiol. 2002, 68, 2101-2105. [CrossRef]

31. Summary and Conclusions. In Proceedings of the Eighty-Third Meeting, Joint FAO/WHO Expert Committee on Food Additives, Rome, Italy, 8-17 November 2016; p. 15.

32. Bondy, G.; Mehta, R.; Caldwell, D.; Coady, L.; Armstrong, C.; Savard, M.; Miller, J.D.; Chomyshyn, E.; Bronson, R.; Zitomer, N.; et al. Effect of long term exposure to the mycotoxin fumonisin $B_{1}$ in p53 heterozygous and p53 homozygous transgenic mice. Food Chem. Toxicol. 2012, 50, 3604-3613. [CrossRef]

33. Escriva, L.; Font, G.; Manyes, L. In vivo studies of fusarium mycotoxins in the last decade: A review. Food Chem. Toxicol. 2015, 78, 185-206. [CrossRef]

34. Müller, S.; Dekant, W.; Mally, A. Fumonisin B1 and the kidney: Modes of action for renal tumor formation by fumonisin B1 in rodents. Food Chem. Toxicol. 2012, 50, 3833-3846.

35. Missmer, S.A.; Suarez, L.; Felkner, M.; Wang, E.; Merril, A.H., Jr.; Rothman, K.J.; Hendricks, K.A. Exposure to fumonisins and the occurrence of neural tube defects along the Texas-Mexico border. Environ. Health Perspect. 2006, 114, 237-241. [CrossRef] [PubMed]

36. European Commission. Commission Recommendation (EC) 2006/576/CE on the presence of deoxynivalenol, zearalenone, ocharatoxin A, T-2 and HT-2 and fumonisins in products intended for animal feeding. Off. J. Eur. Union 2006, L229, 7-9.

37. European Commission. Commission Regulation (EC) No. 1126/2007 on maximum levels for certain contaminants in foodstuffs as regards Fusarium toxins in maize and maize products. Off. J. Eur. Union 2007, L255, 14-17.

38. Silva, J.J.; Viaro, H.P.; Ferranti, L.S.; Oliveira, A.L.M.; Ferreira, J.M.; Ruas, C.F.; Ono, E.Y.S.; Fungaro, M.H.P. Genetic structure of Fusarium verticillioides populations and occurrence of fumonisins in maize grown in Southern Brazil. Crop Prot. 2017, 99, 160-167. [CrossRef] 
39. Sewram, V.; Mshicileli, N.; Shephard, G.S.; Vismer, H.F.; Rheeder, J.P.; Lee, Y.; Leslie, J.F.; Marasas, W.F.O. Production of fumonisin B and C analogues by several Fusarium species. J. Agric. Food Chem. 2005, 53, 4861-4866. [CrossRef]

40. Logrieco, A.; Moretti, A.; Perrone, G.; Mulè, G. Biodiversity of complexes of mycotoxigenic fungal species associated with Fusarium ear rot of maize and Aspergillus rot of grape. Int. J. Food Microbiol. 2007, 119, 11-16. [CrossRef]

41. Lanza, F.E.; Zambolim, L.; da Costa, R.V.; Queiroz, V.A.V.; Cota, L.V.; da Silva, D.D.; de Souza, A.G.C.; Figueiredo, J.E.F. Prevalence of fumonisin-producing Fusarium species in Brazilian corn grains. Crop Prot. 2014, 65, 232-237. [CrossRef]

42. Falavigna, C.; Lazzaro, I.; Galaverna, G.; Dall'Asta, C.; Battilani, P. Oleoyl and linoleoyl esters of fumonisin B1 are differently produced by Fusarium verticillioides on maize and rice based media. Int. J. Food Microbiol. 2016, 217, 79-84. [CrossRef]

43. Marín, S.; Magan, N.; Ramos, A.J.; Sanchis, V. Fumonisin-producing strains of Fusarium: A review of their ecophysiology. J. Food Prot. 2004, 67, 1792-1805.

44. Rocha, L.O.; Barroso, V.M.; Andrade, L.J.; Pereira, G.H.A.; Ferreira-Castro, F.L.; Duarte, A.P.; Michelotto, M.D.; Correa, B. FUM gene expression profile and fumonisin production by Fusarium verticillioides inoculated in Bt and non-Bt Maize. Front. Microbiol. 2015, 6, 1503. [CrossRef] [PubMed]

45. Proctor, R.H.; Brown, D.W.; Plattner, R.D.; Desjardins, A.E. Co-expression of 15 contiguous genes delineates a fumonisin biosynthetic gene cluster in Gibberella moniliformis. Fungal Genet. Biol. 2003, 38, 237-249. [CrossRef]

46. Proctor, R.H.; Plattner, R.D.; Desjardins, A.E.; Busman, M.; Butchko, R.A.E. Fumonisin production in the maize pathogen Fusarium verticillioides: Genetic basis of naturally occurring chemical variation. J. Agric. Food Chem. 2006, 54, 2424-2430. [CrossRef] [PubMed]

47. Stępień, Ł.; Koczyk, G.; Waśkiewicz, A. FUM cluster divergence in fumonisins-producing Fusarium species. Fungal Biol. 2011, 115, 112-123. [CrossRef]

48. Moretti, A.; Mulè, G.; Susca, A.; González-Jaén, M.T.; Logrieco, A. Toxin profile, fertility and AFLP analysis of Fusarium verticillioides from banana fruits. Eur. J. Plant Pathol. 2004, 110, 601-609. [CrossRef]

49. da Silva, V.N.; Fernandes, F.M.C.; Cortez, A.; Ribeiro, D.H.B.; de Almeida, A.P.; Hassegawa, R.H.; Corrêa, B. Characterization and genetic variability of Fusarium verticillioides strains isolated from corn and sorghum in Brazil based on fumonisins production, microsatellites, mating type locus, and mating cross. Can. J. Microbiol. 2006, 52, 798-804. [CrossRef]

50. Covarelli, L.; Stifano, S.; Beccari, G.; Raggi, L.; Lattanzio, V.M.T.; Albertini, E. Characterization of Fusarium verticillioides strains isolated from maize in Italy: Fumonisins production, pathogenicity and genetic variability. Food Microbiol. 2012, 31, 17-24. [CrossRef]

51. Reynoso, M.M.; Chulze, S.N.; Zeller, K.A.; Torres, A.M.; Leslie, J.F. Genetic structure of Fusarium verticillioides populations isolated from maize in Argentina. Eur. J. Plant Pathol. 2009, 123, 207-215. [CrossRef]

52. Momeni, H.; Nazari, F. Population genetic structure among Iranian isolates of Fusarium verticillioides. J. Plant Pathol. Microbiol. 2016, 7, 6. [CrossRef]

53. Tsehaye, H.; Elameen, A.; Tronsmo, A.M.; Sundheim, L.; Tronsmo, A.; Assefa, D.; Brurberg, M.B. Genetic variation among Fusarium verticillioides isolates associated with Ethiopian maize kernels as revealed by AFLP analysis. Eur. J. Plant Pathol. 2016, 146, 807-816. [CrossRef]

54. Olowe, O.M.; Odebode, A.C.; Olawuyi, O.J.; Sobowale, A.A. Molecular variability of Fusarium verticillioides (Sacc.) in maize from three agro-ecological zones of southwest Nigeria. Am. J. Mol. Biol. 2017, 7, 30-40. [CrossRef]

55. Reynoso, M.M.; Torres, A.M.; Chulze, S.N. Fusaproliferin, beauvericin and fumonisin production by different mating populations among Gibberella fujikuroi complex isolated from maize. Mycol. Res. 2004, 108, 154-160. [CrossRef]

56. Beccari, G.; Caproni, L.; Tini, F.; Uhlig, S.; Covarelli, L. Presence of Fusarium species and other toxigenic fungi in malting barley and multi-mycotoxin analysis by liquid chromatography-high-resolution mass spectrometry. J. Agric. Food Chem. 2016, 64, 4390-4399. [CrossRef]

57. Beccari, G.; Colasante, V.; Tini, F.; Senatore, M.T.; Prodi, A.; Sulyok, M.; Covarelli, L. Causal agents of Fusarium head blight of durum wheat (Triticum durum Desf.) in central Italy and their in vitro biosynthesis of secondary metabolites. Food Microbiol. 2018, 70, 17-27. [CrossRef] 
58. Patiño, B.; Mirete, S.; González-Jaén, M.T.; Mulé, G.; Rodríguez, M.T.; Vázquez, C. PCR detection assay of fumonisin-producing Fusarium verticillioides strains. J. Food Prot. 2004, 67, 1278-1283. [CrossRef]

59. SANTE/12089/2016. Guidance Document on Identification of Mycotoxins in Food and Feed; SANTE: Warszawa, Poland, 2016.

60. Stępień, Ł.; Jestoi, M.; Chełkowski, J. Cyclic hexadepsipeptides in wheat field samples and esyn1 gene divergence among enniatin producing Fusarium avenaceum strains. World Mycotoxin J. 2013, 6, 399-409. [CrossRef]

61. Waśkiewicz, A.; Stępień, Ł.; Wilman, K.; Kachlicki, P. Diversity of pea-associated F. proliferatum and F. verticillioides populations revealed by FUM1 sequence analysis and fumonisin biosynthesis. Toxins 2013, 5, 488-503. [CrossRef]

62. Stępień, Ł.; Waśkiewicz, A.; Wilman, K. Host extract modulates metabolism and fumonisin biosynthesis by the plant-pathogenic fungus Fusarium proliferatum. Int. J. Food Microbiol. 2015, 193, 74-81. [CrossRef]

63. Hall, T. BioEdit: An important software for molecular biology. GERF Bull. Biosci. 2011, 2, 60-61.

64. Tamura, K.; Peterson, D.; Peterson, N.; Stecher, G.; Nei, M.; Kumar, S. MEGA5: Molecular evolutionary genetics analysis using maximum likelihood, evolutionary distance, and maximum parsimony methods. Mol. Biol. Evol. 2011, 28, 2731-2739. [CrossRef]

65. Pinheiro, J.C.; Bates, D.M. Mixed-Effects Models in S and S-Plus; Springer: New York, NY, USA, 2000.

66. R Core Team. R: A Language and Environment for Statistical Computing; R Foundation for Statistical Computing: Vienna, Austria, 2017; Available online: https://www.R-project.org (accessed on 10 September 2018).

67. Welch, B.L. The generalization of "Student's" problem when several different population variances are involved. Biometrika 1947, 34, 28-35. [CrossRef]

68. Segvic, M.; Pepeljnjak, S. Distribution and fumonisin B1 production capacity of Fusarium moniliforme isolated from corn in Croatia. Period. Biol. 2003, 105, 275-279.

69. Castella, G.; Bragulat, M.R.; Cabañes, F.J. Mycoflora and fumonisin-producing strains of Fusarium moniliforme in mixed poultry and component raw material. Mycopathologia 1996, 133, 181-184. [CrossRef]

70. Lee, U.S.; Lee, M.Y.; Shin, W.S.; Min, Y.S.; Cho, C.M.; Yoshio, U. Production of fumonisin $B_{1}$ and $B_{2}$ by Fusarium moniliforme isolated from Korean corn kernels for feed. Mycotoxin Res. 1994, 10, 67-72.

71. Nelson, P.E.; Plattner, R.D.; Shackelford, D.D.; Desjardins, A.E. Production of fumonisins by Fusarium moniliforme strains from various substrates and geographic areas. Appl. Environ. Microbiol. 1991, 57, 2410-2412. [CrossRef]

72. Chulze, S.; Ramirez, M.L.; Pascale, M.; Visconti, A. Fumonisin production by, and mating type population of, Fusarium section Liseola isolates from maize in Argentina. Mycol. Res. 1998, 102, 141-144. [CrossRef]

73. Cvetnić, Z.; Pepeljkjak, S.; šegvić, M. Toxigenic potential of Fusarium species isolated from non-harvested maize. Arh. Hig. Rada. Toksikol. 2005, 56, 275-280.

74. Tseng, T.C.; Lee, K.L.; Deng, T.S.; Liu, T.S.; Liu, C.Y.; Huang, J.W. Production of fumonisins by Fusarium species of Taiwan. Mycopathologia 1995, 130, 117-121. [CrossRef]

75. Sanchis, V.; Abadias, M.; Oncins, L.; Sala, N.; Viñas, I.; Canela, R. Fumonisins B1 and B2 and toxigenic Fusarium strains in feeds from the Spanish market. Int. J. Food Microbiol. 1995, 27, 37-44. [CrossRef]

76. Moretti, A.; Bennett, G.A.; Logrieco, A.; Bottalico, A.; Beremand, M.N. Fertility of Fusarium moniliforme from maize and sorghum related to fumonisin production in Italy. Mycopathologia 1995, 131, 25-29. [CrossRef]

77. Plattner, R.D.; Desjardins, A.E.; Leslie, J.F.; Nelson, P.E. Identification and characterization of strains of Gibberella fujikuroi mating population A with rare fumonisin production phenotypes. Mycologia 1996, 88, 416-424. [CrossRef]

78. Vogelgsang, S.; Sulyok, M.; Bäzinger, I.; Krska, R.; Schuhmacher, R.; Forrer, H.R. Effect of fungal strain and cereal susbtrate on in vitro mycotoxin production by Fusarium poae and Fusarium avenaceum. Food Add. Contam. 2008, 25, 745-757. [CrossRef] [PubMed]

79. Ortiz, C.S.; Richards, C.; Terry, A.; Parra, J.; Won-Bo, S. Genetic variability and geographical distribution of mycotoxigenic Fusarium verticillioides strains isolated from maize fields in Texas. Plant Pathol. J. 2015, 31, 203-211. [CrossRef] [PubMed]

80. Gálvez, L.; Urbaniak, M.; Waśkiewicz, A.; Stępień, Ł.; Palmero, D. Fusarium proliferatum - Causal agent of garlic bulb rot in Spain: Genetic variability and mycotoxin production. Food Microbiol. 2017, 67, 41-48. [CrossRef] 
81. Stępień, Ł.; Koczyk, G.; Waśkiewicz, A. Genetic and phenotypic variation of Fusarium proliferatum isolates from different host species. J. Appl. Genet. 2011, 52, 487-496. [CrossRef]

82. Glenn, A.E.; Zitomer, N.C.; Zimeri, A.M.; Williams, L.D.; Riley, R.T.; Proctor, R.H. Transformation-mediated complementation of a FUM gene cluster deletion in Fusarium verticillioides restores both fumonisin production and pathogenicity on maize seedlings. Mol. Plant Microbe Interact. 2008, 21, 87-97. [CrossRef]

(c)

(C) 2020 by the authors. Licensee MDPI, Basel, Switzerland. This article is an open access article distributed under the terms and conditions of the Creative Commons Attribution (CC BY) license (http://creativecommons.org/licenses/by/4.0/). 